\title{
Most Important for First Time Mothers during Labor is to be Respected for their Needs, to Feel Involved in the Care and Support from their Partners
}

Lena Nilsson ${ }^{1}$, Tina Thorsell ${ }^{2}$, Petra Zandren Hammar ${ }^{1}$, Kristina Pethrus ${ }^{2}$ and Anette Ekström ${ }^{1 *}$

${ }^{1}$ School of Life Sciences, University of Skövde, Box 408 SE 541 28, Skövde, Sweden

${ }^{2}$ Department of Obstetrics and Gynecology, Skaraborg Hospital, SE 541 85, Kärnsjukhuset, Skövde, Sweden

\begin{abstract}
Background: Further research is needed about the women's experience of support during labor in order for health professionals to respond to a woman's unique needs.

Aim: To explore first time mothers experience of giving birth as well as professional and social support during labor.

Method: This study was carried out in southwestern Sweden in 2008. A qualitative method with content analysis was chosen for the study. The unit of data is from 14 women's written narratives.

Results: Results show that the women's experiences of being involved in decisions and the relationship to professional and social support during their first labor can be conceptualized as one main theme: "Most important for first time mothers' during labor is to be respected for their needs, to feel involved in the care, and support from their partner". This theme contained three categories: "To be respected for their needs", "To be involved in the care" and "Support from the partner". A safe and calm environment positively influenced the women's sense of support, and the ability to have her partner physically present positively influenced the sense of support.

Conclusion: When healthcare professionals responded to a woman's unique needs during labor, the woman felt that the support was based on her as an individual and possibility to being involved in decisions; otherwise a feeling of uncertainty emerged. If the woman's partner was able to offer support, then it was essential that he was physically present in the room throughout the birth.
\end{abstract}

Keywords: Childbirth, Women's experience, Support

\section{Introduction}

Previous research shows that women in labor consider it important that the midwife provide support and is present while a woman gives birth [1,2].Women also wish to be involved in decision-making, and prefer that the midwife intervene only if the woman asks her to or if the natural process is disturbed [3]. Childbirth is an important event in a woman's life. It is therefore important that the midwife understands the woman's needs and supports her according to her own capacity [4-6]. When the woman trusts the midwife, she will have greater confidence, which will help her give birth, handle the pain, and a feeling of becoming a better mother. One role of the midwife is to assist a woman in interpreting her body's signals during the process of childbirth [2]. Mothers also want a trustful relationship with her partner and appreciate support from him during childbearing [7-10] which contribute to the mother feeling safe $[11,12]$.

Hupcey \& Morse describe the importance to define and maintain the distinction between social and professional support [13]. Social support is offered by relatives or friends within the individuals own network [14] while professional support is offered by professionals and is limited by professional knowledge and should aim to strengthen social support [13]. Important for women's experience to feel safe during childbirth is professionals supportive presence [15] and meeting women's unique individual needs such as being seen and listened to [16,17]. Continuous support during childbirth can be provided by professionals and as social support, aims to see the women as individuals based on a humanistic perspective has a positive effect on women, such as providing a feeling of calm [2]. Every effort should bemade to ensure that women's birth environmentsare empowering, nonstressful, communicaterespect and are not characterized by routine interventions that addrisk without clear benefit [2]. In order to give optimal birth environments to women during laborthe presentstudy aims to explorefirst time mothers experience of giving birth as well asprofessional and social support during labor.

\section{Methods}

A qualitative design with a content analysis was chosen for this study [18]. Written narratives were found to be the most suitable data collection method for the present study in order to catch the women's freely described experiences of their first experience of giving birth. Content analysis is a stepwise process of categorization based on the expression of thoughts, feelings, and actions described throughout the text. The intentions of the analytical process are to remain close to the words of the text and to bring out the contextual meanings. Content analysis can be either manifest or latent, depending on the depth and level of abstraction. Manifest content is about the actual text, while latent content describes what the text is talking about [18]. For this study, latent content analysis was chosen to identify specific meanings in the women's narratives about first time mothers experiences of of giving birth as well asprofessional and social support during labor. The

*Corresponding author: Anette Ekström, School of Life Sciences, University of Skövde, Box 408 SE 541 28, Skövde, Sweden, Tel. +46 5004484 14:E-mail anette.ekstrom@his.se

Received May 25, 2012; Accepted June 18, 2012, 2012; Published June 20 , 2012

Citation: Nilsson L, Thorsell T, Hammar PZ, Pethrus K, Ekström A (2012) Most Important for First Time Mothers during Labor is to be Respected for their Needs, to Feel Involved in the Care and Support from their Partners. J Nurs Care 1:114 doi:10.4172/2167-1168.1000114

Copyright: $\odot 2012$ Nilsson L, et al. This is an open-access article distributed under the terms of the Creative Commons Attribution License, which permits unrestricted use, distribution, and reproduction in any medium, provided the original author and source are credited. 
Citation: Nilsson L, Thorsell T, Hammar PZ, Pethrus K, Ekström A (2012) Most Important for First Time Mothers during Labor is to be Respected for their Needs, to Feel Involved in the Care and Support from their Partners. J Nurs Care 1:114. doi:10.4172/2167-1168.1000114

Page 2 of 5

\begin{tabular}{|l|l|l|l|}
\hline \multicolumn{1}{|c|}{ Sentence } & Condensed sentence & Subcategories & Categories \\
\hline $\begin{array}{l}\text { When my partner had to leave the room to buy food or } \\
\text { pay for parking the car, or when the professionals told } \\
\text { my partner to move aside, I felt alone. It was important } \\
\text { that my partner could be close all the time for me to feel } \\
\text { safe. }\end{array}$ & $\begin{array}{l}\text { My partner's physical } \\
\text { presence was important. } \\
\text { When I felt my partner's } \\
\text { presence, I felt supported. }\end{array}$ & $\begin{array}{l}\text { The physical presence } \\
\text { of the women's partner }\end{array}$ & $\begin{array}{l}\text { My partner was my } \\
\text { lifeline }\end{array}$ \\
\hline $\begin{array}{l}\text { Most important for first time mothers' } \\
\text { during labor is to be respected for } \\
\text { their needs, to feel involved in the } \\
\text { care, and support from their partners }\end{array}$ & \\
\hline
\end{tabular}

Table 1: Process of analysis.

\begin{tabular}{|l|l|}
\hline Main categories and subcategories & \\
\hline $\begin{array}{l}\text { To be respected for their needs } \\
- \text { The presence of the midwife }\end{array}$ & \\
- Being able to eat solid food & Most important for first time mothers' during labor is to be to be respected for their needs, \\
- Opportunity to prepare for the birth & to feel involved in the care, and support from their partner \\
\hline $\begin{array}{l}\text { To feel involved in the care } \\
- \text { The right to choose adequate pain relief }\end{array}$ & \\
\hline $\begin{array}{l}\text { Support from the partner } \\
- \text { My partner was my a lifeline }\end{array}$ & \\
\hline
\end{tabular}

Table 2: Theme with the three main categories and the six subcategories identified from narratives from the first time mothers experiences of giving birth as well as professional and social support during labor.

stepwise process of categorization is presented in the section on data generation and analysis.

\section{Study site and participants}

This study was undertaken from February to April 2008 in a hospital labor ward in a southwestern county in Sweden consisting of 280,000 inhabitants. In 2006, there were 2204 births to 914 first-time mothers. Women with both uncomplicated and complicated pregnancies are admitted to the labor ward. Continuous support during childbirth by professionals is not routinely offered in the labor ward. There are four to six midwifery students attend clinical education at the labor ward at the same time for around 30 weeks annually.

The inclusion criteria for the present study were Swedish-speaking, first-time mothers who gave birth vaginally, had healthy infants, when discharged from the hospital. In addition the women should not have been cared for by the authors of this study. The midwives in the maternity ward asked women who fit the inclusion criteria to participate in the study. The midwives provided information about the study, its objectives, and the rights of the research participants orally and in a leaflet. The women were asked to freely describe their experience of giving birth to their first child on at least one page. Written narratives were obtained from 14 women, 1 to 2 weeks after childbirth. The written narratives were two to seven pages. Data collection and part of the analysis were carried out simultaneously to follow up on the issues that were emerging [19].

\section{Data generation and analysis}

The written narratives were transcribed verbatim and analyzed separately by the authors using content analysis according to the method developed by Lundman and Graneheim [18]. In short, the transcripts from the women were scrutinized several times, discussed, compared, and validated by all authors. Familiarity with the text was achieved with repeated reading. Words and sentences containing information relevant to the research questions were identified as meaning units, which were condensed and coded. The codes were grouped under subcategories and then organised into categories. Data were further analyzed by reading across the categories, searching for new associations and meanings in the data. In the final step, findings were discussed and reflected upon, taking the research issues into account and an overall theme (Table 1) [18].

\section{Ethical approval}

Ethical permission to undertake the study was given by the School of Life Science, University of Skövde, Sweden. The clinical head of service for the hospital gave access to under-take this study at the hospital labor ward.

\section{Results}

The women described the importance of their partner's involvement, which provided a shared childbirth experience. The women also felt that it was important to feel support from their midwife during childbirth. The possibility of making their own choices regarding eating or receiving pain relief, as well as feeling safe and having peace and quiet were important for the women's childbirth experience. The women's experiences and reflections on receiving support were presented as a single main theme: 'Most important for first time mothers' during labor is to be respected for their needs, to feel involved in the care, and support from their partner". This theme contained three categories: "To be respected for their needs", "To be involved in the care" and "Support from the partner" Six subcategories are presented in Table 2. Each category and its subcategories were presented using direct quotations in a conversational format. A code number for each respondent is included after the quotation (Narratives N 1-N 14).

\section{To be respected for their needs}

The presence of the midwife: Before arriving at the maternity ward, women call the clinic to receive professional support or to ask questions. The midwife gives support over the phone and tries to prepare the women for what will come. The women who felt that their midwife had supported them and had been there for them had a more positive experience than those who did not feel that type of support from their midwife. In contrast, the women also described that they found the maternity ward stressful and that experience made them feel uncertain and insecure. The respondents wished that the professionals had been more discreet. Knowing that professionals felt stress created disorder around the women in labor. Because of high pressure on midwives due to a shortage of staff, the patients suffered. Some felt the pressure during the births of their children, and it made the women worried and uncertain."The midwife was much stressed and had to leave the room all the time."(N4). "My midwife was in our room with us most of the time and that felt very good" (N2) "When everything was over, we were left alone in the room. That was very nice, everything became peaceful 
and quiet" (N3). The women described that one of the most important things for them during labor was their midwife's support and presence. After giving birth, the women expressed that it was important that the professionals made it possible for the new family to be alone with each other in peace and quiet. If they were offered that opportunity, they felt closer to each other as a new family.

Being able to eat solid foods: The women were not allowed to eat solid food if the contractions were regular and the birth had started after they arrived at the delivery ward in which this study took place: "I got the advice to eat a lot and try to rest as much as I could before we came in" (N14)". Some women wrote that they felt out of energy, and they were worried where they would find their strength to be able to give birth in that condition: "I felt hungry because I hadn't been eating during the day. And by then I felt lost" (N1).The women felt that if they had been listened to and allowed to eat solid food they would have felt much stronger and secure. They described that they were disappointed of the rules about not been able to eat at the delivery ward.

Opportunity to prepare for the birth: The women described that they had imagined their childbirth experience would be special. They had been preparing for this special moment for 9 months. They had prepared themselves by reading books or taking classes focused on giving birth. Some women said that they had not felt afraid about giving birth before their experience, but afterwards they were afraid. They described that their fear was because their childbirth experience had not have turned out the way that they had hoped: "My delivery did not turn out as I had imagined it. The delivery was far worse than I had expected it to be" (N1). The women's disappointment had different reasons, but one thing they described as a disappointment was that the procedure did not turn out the way they had imagined. They described being disappointed with the anesthetic team: they had to wait too long to get an epidural; some had to wait an hour. The women wished that someone had informed them earlier that if they wanted an epidural it could take time. If they had known beforehand, they would have been more prepared for the labor.

\section{To feel involved in the care}

The right to choose adequate pain relief: The women noted that they felt disappointed with the pain relief method that had been offered to them. Some felt that it was not their own wish and that they would have chosen another pain relief method if the midwife had given more options. Some said that they might have wanted to try some other things before they were offered an epidural or other medical pain relief. For example, N6 said, "We went into the delivery room, and I started with gas. And I had thought that I would have been offered to take a bath or to get some acupuncture". They would have wanted to begin with complementary methods of pain relief instead of traditional medical treatment.

The right to choose whether students should be involved: The women felt that they wanted the right to choose if students were involved during their labor. When this option was not considered by the midwife, the women felt that their self-determination was taken away from them. When the woman was in labor and had pain, she felt that she did not want two persons to do examinations each time. She felt that she would have wanted to be left alone more. N4 stated, "The professionals didn't even ask us if it was all right that there was a student involved in my labor. All examinations were done twice, and that felt very difficult, especially when you are in labor". She also noted, "When we asked if they could do the examination every other time, the midwives answered us that this hospital was a teaching hospital!" When the women were not entitled to participate in their own choices during labor, it resulted in negative experiences.

\section{Support from the partner}

My partner was my lifeline: The women observed that it was very important that their partner could support them and that the conditions in the room helped their partner to support them. When their partner had to leave the room to buy food, pay for parking the car, or when the professionals told their partner to move aside, the women felt that they were not listened to. The women felt alone and felt it was important that they were not left alone by their husbands or partners during this important event in their lives. A partner's physical presence was thus important to the woman in labor. When she felt her partner's presence, she felt more calm and secure. For example, N1 observed, " $M y$ husband was my lifeline". The women described that their husbands/ partners missed a big part of the labor when they had to leave the room for different reasons that they did not choose for themselves and as a consequence the women felt alone.

Most important for first time mothers' during labor is to be respected for their needs, to feel involved in the care and support from their partner: The women described that they felt calm when they were well informed about what was happening during their labor, and when the midwife was calm, they felt calm. The women needed to feel support from their partner with regard to his physical presence, and appreciated health professionals who made it possible for them to be involved in their own options during labor. The women needed to feel safe and listened to, and to have the right to be involved in their own choices regarding food and pain relief during labor. If the women received the opportunity to participate in making an informed choice, they felt supported and in control of the situation, and thus, they had a better childbirth experience.

\section{Discussion}

The main results of the present study show women's experiences of support and being involved during their first labor depend on whether the healthcare professionals responded to the woman's unique needs. If the woman felt that the support was good and was based on her as an individual and gave her the possibility to be involved, otherwise, a feeling of uncertainty emerged. The women also described the presence of their partner as an important part of the childbirth experience; she wanted to share the experience with the partner.

The results of the present study showed that women who felt that their midwife had supported them and had been there for them had a more positive experience than those who did not feel that support from their midwife, which is in agreement with Waldenström's findings [1]. A stressful environment in the maternity ward made the women feel uncertain and insecure. Previous research shows that continuous support was important for women during childbirth in order to perceive a positive childbirth experience [2]. The first time mothers in the present study stated that when the midwife left the room they felt alone and desired that the midwife should be with her.

The women experienced a feeling of disappointment from the professionals if they arrived at the delivery ward too early during their labor. When the women decided to come to the delivery ward, it is thus important that the professionals make them feel welcome, safe, and secure, by seeing and respecting them as individuals [20,21]. When the women in this study were not entitled to participate in their own choices during labor, the women often had a negative birth experiences. Other research shows the importance of seeing women as a unique 
Citation: Nilsson L, Thorsell T, Hammar PZ, Pethrus K, Ekström A (2012) Most Important for First Time Mothers during Labor is to be Respected for their Needs, to Feel Involved in the Care and Support from their Partners. J Nurs Care 1:114. doi:10.4172/2167-1168.1000114

Page 4 of 5

individual and to have an understanding of childbirth as a life-changing event $[1,3,21]$.

In the present study, the partner's support was mentioned more often than health professionals' support, as an important factor contributing to a positive childbirth experience. The partner is referred to as the women's lifeline, and the importance of spending time together with the partner during childbirth is often expressed. Despite this, the women's narratives showed that some of the routines at the delivery ward did not conform to the women's desires. Earlier research shows that women in labor value their partner's support, and psychological and emotional expressions of caring, empathy and sympathy are important when women giving birth feel frightened and vulnerable $[2,7,11]$. The women's partner wants to be seen as individuals who are part of the laboring couple. If they are left out, they tend to feel helpless; this can result in a feeling of panic and can put their supportive role of their partner at risk [22].

Since the women in this study described that they were disappointed about the rules about not being able to eat during labor after they had arrived at the delivery ward. During labor, solid food can promote a positive childbirth experience, and if given a choice, an equal number of women choose solid and non-solid foods during labor [23]. Recent research shows that if a woman is at no risk for operative birth with general anesthesia, it is proposed to let the women decide if she wants to eat during labor or not [23]. Denying a woman in labor solid foods can increase her perception of pain, which in turn may affect the labor procedure and lead to more medical interventions [24]. The women also described that they felt disappointed about the pain relief method that had been introduced. Some of the women in this study said that they might have wanted to try non-medical pain relief before they were offered medical pain relief. Not having the possibility to choose a pain relief method contributed to a feeling of disappointment about their labor experience. Earlier research shows that when a woman has a feeling of being safe and secure she will lower her perception of pain, and thereby the risks involved in medical intervention [2]. If women have the opportunity to participate in an informed choice, they felt supported and in control of the situation. Thus, they had a better childbirth experience [2].

Qualitative design with content analysis was used in this study to describe the anonymous narratives written by the women from "their heart" and sometimes very emotional to read. The narrative content depended on the women's capability to express themselves in words. This method gave a wide variation of results, and the women described their own experiences without any interference from the authors. This study resulted in 14 narratives that varied greatly. Throughout the study, different steps were considered to enhance the trustworthiness of the study [25].The study is limited by its small sample size, but the context and the participants are described as clearly as possible to facilitate the transferability of the results $[18,19]$.

More research is also required regarding the type of food that women need during labor in order to provide the best physical and mental conditions for the labor experience. In general, we need to know more about a woman's childbirth experience to be able to create good care for her and her partner. In order to provide women with the care and support they desire, we need to know more about what makes the childbirth experience positive. Therefore, more research is needed to create a care system based on evidence from the actual experiences and wishes of women and their partners.

\section{Conclusion}

This study shows that when healthcare professionals responded to women's unique needs during labor, the woman felt that the support was good and was based on her as an individual and gave her the possibility of being involved in decisions. When healthcare professionals did not respond to women's unique needs during labor, a feeling of uncertainty emerged. If the partner is able to offer support, it is essential that he be physically present in the room throughout the labor.

\section{Acknowledgments}

This study was supported by the Skaraborg Institute for Research and Development, School of Life Sciences at Skövde University and the Science Committee, Central Hospital, Skövde.

\section{References}

1. Waldenström U (1999) Experience of labor and birth in 1111 women. Psycosom. Res 47: 471-482.

2. Hodnett ED, Gates S, Hofmeyr GJ, Sakala C, Weston J (2011) Continuous support for women during childbirth. CD003766.

3. Lundgren I, Berg M (2007) Central concepts in the midwife-woman relationship Scand J Caring Sci 21: 220-228.

4. Halldórsdóttir S, Karlsdóttir SI (1996) Empowerment or discouragement women's experience of caring and uncaring encounters during childbirth. Health Care Women Int 17: 361-379.

5. Leap N, Sandall J, Buckland S, Huber U (2010) Journey to Confidence: Women's Experiences of Pain in Labour and Relational Continuity of Care. $J$ Midwifery Womens Health 55: 234-242.

6. Lundgren I (2004) Releasing and relieving encounters: experiences of pregnancy and childbirth. Scand J Caring Sci 18: 368-375.

7. Somers-Smith MJ (1999) A place for the partner? Expectations and experiences of support during childbirth. Midwifery 15: 101-108.

8. Kainz G, Eliasson M, von Post I (2010) The Child's Father, an Important Person for the Mother's Well-Being During the Childbirth: A hermeneutic Study. Health Care Women Int 31: 621-635.

9. Löf M, Svalenius EC, Persson EK (2006) Factors that influence first-time mothers' choice and experience of early discharge. Scand J Caring Sci 20 : 323-330.

10. Gibbins J, Thomson AM (2001) Women's expectations and experiences of childbirth. Midwifery 17: 302-313.

11. Ekström A, Widström AM, Nissen E (2003) Breastfeeding Support from Partners and Grandmothers: Perceptions of Swedish Women. Birth 30: 261-266.

12. Raphael-Leff J (2005) Psychological processes of childbearing. (4th edn), Anna Freud Centre, Guildford.

13. Hupcey J, Morse JM (1997) Can a professional relationship be considered Social Support? Nurs Outlook 45: 270-276.

14. Langford CP, Bowsher J, Maloney JP, Lillis PP (1997) Social support: a conceptual analysis. J Adv Nurs 25: 95-100.

15. Kennedy HP, Grant J, Walton C, Shaw-Battista J, Sandall J (2010) Normalizing Birth in England: A Qualitative Study. J Midwifery Womens Health 55: 262-269.

16. Walsh DJ (2006) "Nesting" and "Matrescence" as distinctive features of a freestanding birth centre in the UK. Midwifery 22: 228-239.

17. Walsh D, Downe S (2010) Essential midwifery practice: intrapartum care. Blackwell Publishing Ltd, Oxford.

18. Lundman B, Graneheim HU (2004) Qualitative content analysis in nursing research: concepts, procedures and measures to achieve trustfulness. Nurse Educ Today 24: 105-112.

19. Mayan M (2001) An Introduction to Qualitative Methods: A Training Module fo Students and Professional. Qual Institute Press, Alberta.

20. Kalkas H, Sarvimäki A (1987) Ethical Grounds in Nursing. Nordstedts Stockholm. 
Citation: Nilsson L, Thorsell T, Hammar PZ, Pethrus K, Ekström A (2012) Most Important for First Time Mothers during Labor is to be Respected for their Needs, to Feel Involved in the Care and Support from their Partners. J Nurs Care 1:114. doi:10.4172/2167-1168.1000114

21. Berg M, Lundgren I, Hermansson E, Wahlberg V (1996) Women's experience of the encounter with the midwife during childbirth. Midwifery 12: 11-15.

22. Bäckström C, Hertfelt-Wahn E (2011) Support during labour: first-time fathers' descriptions of requested and received support during the birth of their child. Midwifery 27: 67-73
23. Singata M, Tranmer J, Gyte GM (2010) Restricting oral fluid and food intake during labor. Cochrane Database Syst Rev, CD003930.

24. The CNM Data Group 1996 (1999) Oral intake in labor. Trends in midwifery practice. J Nurse-Midwifery 44: 135-138.

25. Lincoln YS, Guba EG (1985) Naturalistic Inquiry. Sage Publications, California. 